University of Louisville

ThinkIR: The University of Louisville's Institutional Repository

\title{
The effect of predator positioning and related angles on the flight- initiation distance and refuge choice of the eastern gray squirrel.
}

Lindsay Nason

University of Louisville

Follow this and additional works at: https://ir.library.louisville.edu/honors

Part of the Biology Commons

\section{Recommended Citation}

Nason, Lindsay, "The effect of predator positioning and related angles on the flight-initiation distance and refuge choice of the eastern gray squirrel." (2015). College of Arts \& Sciences Senior Honors Theses.

Paper 37.

http://doi.org/10.18297/honors/37

This Senior Honors Thesis is brought to you for free and open access by the College of Arts \& Sciences at ThinkIR: The University of Louisville's Institutional Repository. It has been accepted for inclusion in College of Arts \& Sciences Senior Honors Theses by an authorized administrator of ThinkIR: The University of Louisville's Institutional Repository. This title appears here courtesy of the author, who has retained all other copyrights. For more information, please contact thinkir@louisville.edu. 
The Effect of Predator Positioning and Related Angles on the FlightInitiation Distance and Refuge Choice of the Eastern Gray Squirrel (Sciurus carolinensis)

\author{
By \\ Lindsay Nason \\ Submitted in partial fulfillment of the requirements \\ for Graduation (summa or magna) cum laude \\ and \\ for Graduation with Honors from the Department of Biology \\ University of Louisville
}

April, 2015 


\begin{abstract}
The purpose of this study was to determine the effect that the relative positions of squirrel, predator, and refuges, as well as the predator's SPT angle (See Figure 1), had on a squirrel's choice of refuge and the length of its flight initiation distance. A running person was used to simulate an attacking predator, and the relative positions of squirrel, person, and refuges were measured using both distance and compass angle. Data were collected in September and October 2014 at several urban green spaces in Louisville, Kentucky.
\end{abstract}

The SPT angle measurement was not found to be particularly useful in predicting flight initiation distance or the squirrel's refuge of choice. The distance of the person to the refuge (PTR) was found to be significantly correlated with flight initiation distance. However, the correlation was positive, the opposite relationship to what had been expected. Assessment of refuge choice by comparing the relative positions of squirrel, person, and refuges was highly successful. It was found that squirrels employ both escape trajectory and the relative distances of the squirrel and the person to a particular refuge (expressed as the PTR/STR ratio) when they select a refuge. Instead of always running to the closest tree (defined as tree 1), the squirrels select a refuge that provides them the best combination of relative squirrel/predator distances and an escape trajectory that takes them away from the predator's path.

\title{
Table of Contents
}

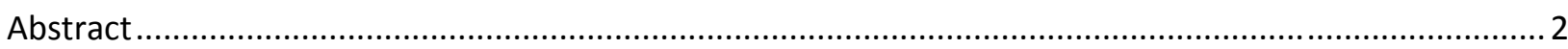




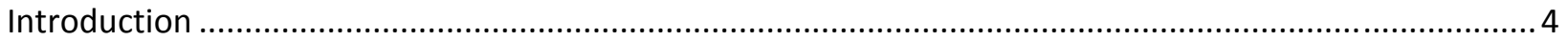

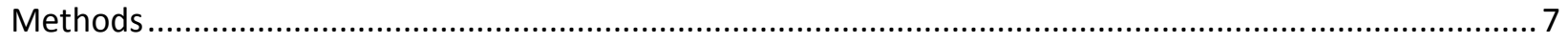

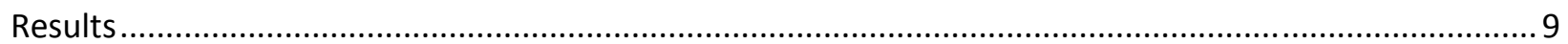

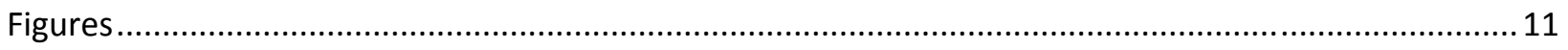

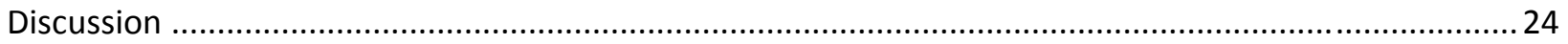

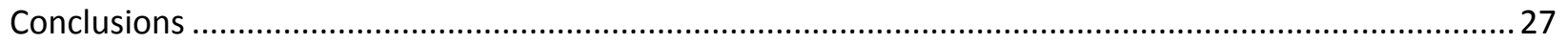

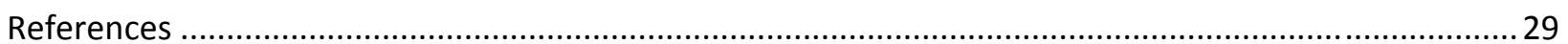

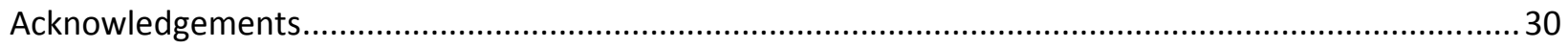




\section{Introduction}

Flight initiation distance, or the distance at which an animal flees before an approaching threat, is a useful means of quantifying an animal's ability to assess risk, because the animal is forced to perform a cost-benefit analysis before fleeing (Cooper and Frederick 2007). Many studies have shown the varied approaches different species take to assess risk. Fong et al. (2009) determined that to the white-browed sparrow-weaver (Plocepasser mahali), variation in indirect risk (distance from cover) was more important to the bird's risk-assessment than variation in direct risk (distance from humans). Similarly, it was shown in a different study that flight initiation distance has a positive correlation with distance from a refuge in a phrynosomatid lizard (Cooper and Wilson 2007).

Other studies have noted the importance of direct risk: Cardenas et al. (2005) showed that galahs (Cacatua roseicapilla), a type of Australian parrot, systematically flee humans when they are approached to within $44 \%$ of their alert distance, i.e. the distance between an approaching threat and a potential prey when the prey stops other activities to monitor the threat. Additional studies have noted that flight initiation distance is affected by the behavior of a potential predator. For example, Eason et al. (2006) found that American robins are more likely to display a longer flight initiation distance if the approaching human is gazing directly at them and on an established footpath rather than in an open field. A meta-analysis of risk assessment performed by Stankowich and Blumstein (2005) concluded that predator traits and increased distance of a prey animal from a refuge both consistently increase the potential prey’s perception of risk, and therefore flight initiation distance. Other researchers have assessed factors such as light level (Cloyed and Eason 2015), the presence of a mating opportunity (Cooper 2011), level of 
concealment (Camp et al. 2012), body size (Cloyed and Eason 2015), and the gender of the animal approached (Guay 2013).

In this study, I investigated the responses of eastern gray squirrels in urban parks to an approaching human, focusing on their flight initiation distance, their choice of refuge (a tree), and the relative positions of the focal squirrel, the approacher, and the potential and selected refuges. Some previous studies have noted the effect of human activity on flight initiation distance. One, conducted by Rodriguez-Prieto et al. (2009), showed that blackbirds found in areas with high human traffic experienced combined habituation and risk allocation effects that resulted in flight initiation distances significantly shorter than those displayed by blackbirds found in low human traffic areas. Similarly, a study conducted on eastern gray squirrels found that flight initiation distance decreased with increased levels of human exposure (Engelhardt and Weladji 2011). These effects will likely be reflected in the results of this study, as the squirrels are being targeted in urban areas.

The first variable of interest in this study is the angle marked SPT in the predator-preyrefuge triangle (See Figure 1). Little previous work has been done to correlate this type of angle with flight initiation distance. However, some studies have included more basic elements of directionality. A study conducted by Fernandez-Juricic et al. (2005) discovered that 4 out 5 of the grassland bird species they observed demonstrated greater flight initiation distances when approached tangentially rather than directly, counteracting the generally-held theory that directness of approach is positively correlated with flight initiation distance (Stankowich and Blumstein 2005). This result lends credence to the idea that various angles between predator, prey, and refuge could have highly variable effects on flight initiation distance, and it is the 
prediction of this study that there will be statistically significant differences in flight initiation distance depending on the measure of angle SPT.

The second variable of interest in this study is the location of the predator relative to both the focal animal and the potential areas of refuge. A study conducted by Kramer and Bonenfant (1997) found that flight initiation distance in woodchucks increased significantly when the predator was positioned between the woodchuck and its burrow. In that study, the woodchuck had only one source of refuge (the burrow), and was forced to run toward the predator to reach it. By contrast, the focal animals (squirrels) in this study will have multiple sources of refuge available to them, in the form of nearby trees. It is the prediction of this study that the focal squirrel will seek refuge in a tree that is located in a direction away from the approach of the predator, even if a tree in the approach path is physically closer to the squirrel, with one important caveat. Another key prediction of this study is that the squirrel will attempt to maximize the person-to-tree/squirrel-to-tree ratio. In other words, the squirrel should choose the tree that is both close to it and far from the threat. Given a sufficiently large ratio, a squirrel may choose a refuge that would require it to run towards the threat.

One method by which the relative positions of person, squirrel, and refuge will be analyzed is with a circular escape trajectory histogram. A circular escape trajectory histogram shows the direction an animal has fled on a $360^{\circ}$ scale, and is able to visually depict the squirrelchase scenarios being conducted in this study, though it will not display the position of all three trees. According to Domenici et al. (2011), an escape trajectory histogram drawn for an animal that flees to a refuge will show all trajectories clustered very tightly around the location of that refuge. However, the model used by Domenici et al. involves only one possible refuge. In each scenario conducted in this study, the squirrel will have at least 3 potential refuges, and over the 
entire course of data collection, there should be refuges located in almost every section of the circle. As animals typically avoid fleeing towards an oncoming threat, the escape trajectory histogram for this study will be expected to show the bulk of trajectories on the top half of the diagram, above the $90-270^{\circ}$ plane.

\section{Methods}

Certain parameters were met before data were collected on any individual: 1) The potential focal squirrel was foraging and not obviously paying attention to the researchers; 2) The squirrel was in an open area in the vicinity of at least 3 trees at least $25 \mathrm{~cm}$ in diameter at breast height and more than $8 \mathrm{~m}$ in height and thus mature enough to provide a suitable refuge;

3) The squirrel was at least 2 meters from the base of any one tree; 4) The researchers were at least 10 meters away from the squirrel; and 5) The trees were widely spaced enough to create significant distinctions in distance or angle between each tree and the squirrel. After these parameters were met, the data for this study were collected in the following manner. One person acted as a runner, and two acted as observers. The runner used a rock to mark the starting point, and then ran in a straight line towards the squirrel, moving at the fastest pace possible for the runner. When the squirrel alerted, i.e. stopped foraging and looked in the direction of the runner, the runner dropped a second rock to mark the alert distance. When the squirrel fled, the runner dropped a third rock to mark the flight initiation distance. Meanwhile, the observers noted the position of the squirrel at the start, the direction it was facing before alerting, and the refuge selected by the fleeing squirrel. A tape measure was then used to record all the relevant distances. These included three measures of the distance between person and the focal squirrel: start distance (distance from person to squirrel at the beginning of the trial), alert distance (distance at which the squirrel alerted to the approaching person), and flight initiation distance 
(distance at which the squirrel fled). The distance between the squirrel and the three closest trees of suitable size to serve as a refuge was also measured, with tree 1 defined as the tree nearest the squirrel and tree 3 as the farthest. Finally, the distance between the approaching person and these trees was measured from the person's location when the squirrel fled. A sighting compass was used to record compass directions of interest: the direction from person to squirrel when the squirrel fled, direction the squirrel was facing, and the directions from squirrel and from person to trees 1, 2, and 3. As with the distances between person and trees, the compass directions from person to the three trees were measured from the location of the person when the squirrel fled, because it is at this point that the squirrel has made its choice of refuge. A simple sketch was also drawn to note the relative spatial positions of the runner, focal squirrel, and refuges. Compass directions were used to calculate angles between the squirrel and its potential refuges, between the approaching person and the squirrel, and between the person and the squirrel's potential refuges; the field sketch was used to verify these angles. If a fourth tree was an equal distance from the squirrel when it fled as was the third tree, measurements of distances and directions were also taken for that tree; similarly, if a squirrel selected a tree more distant than the third tree, distances and directions were measure for that tree and all nearer trees of suitable size, with resulted in four or five trees being included for some focal squirrels. All of the data were collected in an urban setting, as only parks and university campuses contain mature trees spaced widely enough apart to fit the parameters of the study. Data were collected in September and October 2014 at the following Louisville locations: The University of Louisville, Triangle Park, Central Park, Shawnee Park, Tom Sawyer Park, and George Rogers Clark Park. 


\section{Results}

A total of 67 squirrels were sampled in this study. In each of the chase scenarios, the relative spatial positions of the focal squirrel, the runner, and each potential refuge was marked by distance and compass direction. The triangle formed between squirrel, person, and refuge contains three measurable angles. The angle of interest, SPT, is marked in Figure 1. To measure SPT, the focal squirrel was marked at $0^{\circ}$, the person was placed on the $90^{\circ}$ plane, and all angles were recorded between $0-180^{\circ}$ regardless of side. A linear regression was performed comparing SPT angle to flight initiation distance. This resulted in a statistically significant (P-value .001) negative relationship. This means that flight initiation distance decreased as the SPT angle increased. However, only $15 \%$ of the data was explained by the trendline. A scatterplot of these data is shown in Figure 2. The average SPT angle was significantly larger in the group of squirrels that took an escape trajectory "towards" the oncoming threat (two-tailed t-test gave a Pvalue of .01) than in the group of squirrels that took an "away" trajectory. For this reason, separate linear regressions were performed comparing the SPT angles and flight initiation distances of the two groups. For the "towards" group, the resulting negative relationship was statistically significant (P-value-.002) and 38\% of the data was explained by the trendline. A scatterplot of these data is shown in Figure 3. For the "away" group the resulting negative relationship is also significant (P-value-.03) but only $11 \%$ of the data is explained by the trendline. A scatterplot of these data is shown in Figure 4.

Linear regression was also performed on the relationship between person-to-refuge (PTR) distance and flight initiation distance. The result was a highly significant positive relationship (P value $<.001$ ), meaning that flight initiation distance increased the further the person was away from the chosen refuge. The trendline explained 29\% of the data (Figure 5). To determine 
whether or not this relationship was different when the squirrel chose the closest tree (tree 1), linear regression was performed comparing the PTR distance and FID of squirrels that chose tree 1. This also resulted in a highly significant positive relationship (P value $<0.001$ ), and $71 \%$ of the data was explained by the trendline (Figure 6). To determine the potential influence of STR distance on the PTR-FID relationship, a linear regression was performed that correlated PTR distance and STR distance. The result was a positive correlation of high significance (P value < 0.001), meaning that STR distance generally increased with PTR distance. The trendline explained $29 \%$ of the data. A scatterplot of these data is shown in Figure 7. To determine if STR distance wholly explained the PTR-FID relationship, linear regression was performed comparing STR distance with flight initiation distance. No statistically significant trendline resulted. A scatterplot showing STR distance graphed against flight initiation distance is shown in Figure 8.

A circular escape trajectory histogram (Figure 9) was generated for the data set. The threat (represented by the person) is placed at the $0^{\circ}$ mark and the focal squirrel is placed at the center point. The original compass data were standardized such that the line between the person and the focal squirrel is always represented by $180^{\circ}$. The histogram is divided into $10^{\circ}$ intervals, and each concentric ring represents one squirrel that took an escape trajectory within a particular interval. Escape trajectories that fell in the $90-269^{\circ}$ range were considered to be "away" trajectories. Escape trajectories that fell in the $270-89^{\circ}$ range were considered to be "towards" trajectories. 40 out of 67 squirrels recorded “away” trajectories and 27 out of 67 recorded “towards” trajectories.

A 2x2 contingency table was used to examine the relationship between the trajectory of tree 1 and the selection (or not) of tree 1. (Table 1). (Note: when a squirrel was forced by 
scenario constraints to have to run towards the person, the escape path with the shallowest angle was included in the "Away” category.) A Fisher's Exact Test was performed on these data, and the resulting P-value was 0.0361 , meaning that the trajectory of tree 1 had a significant influence on whether or not it was chosen. Specifically, 30 out of 44 squirrels rejected tree 1 if it was located in the direction of the person. A 2x2 contingency table was also used to examine the relationship between refuge selection and escape trajectory. (Table 2). Squirrels were sorted into two groups: selection of tree 1 and selection of a farther tree. Because squirrels have a strong inclination to run to the closest tree, this distinction is of far more importance than the distinction between trees 2 and 3. A Fisher's test on these data resulted in a P-value of 0.0173, meaning that there is a significant correlation between escape trajectory and refuge choice. This is most clearly seen in the group "other" in which 31 out of 39 squirrels chose an "away" escape trajectory.

A 2x2 contingency table was used to examine the relationship between maximizing the PTR/STR ratio and selection of refuge. (Table 3). A Fisher's test on these data resulted in a Pvalue of 0.003 , meaning that there is a significant correlation between maximizing the PTR/STR ratio and choosing a refuge. This is shown most strongly in the squirrels that chose tree 1 , because 25 out of the 28 squirrels that chose tree 1 were choosing the refuge with the highest PTR/STR ratio. Highest ratio is not a good predictor for the "other” group; however, 35 out of 39 squirrels in this group ran to a refuge with either the highest or second-highest ratio.

\section{Figures}




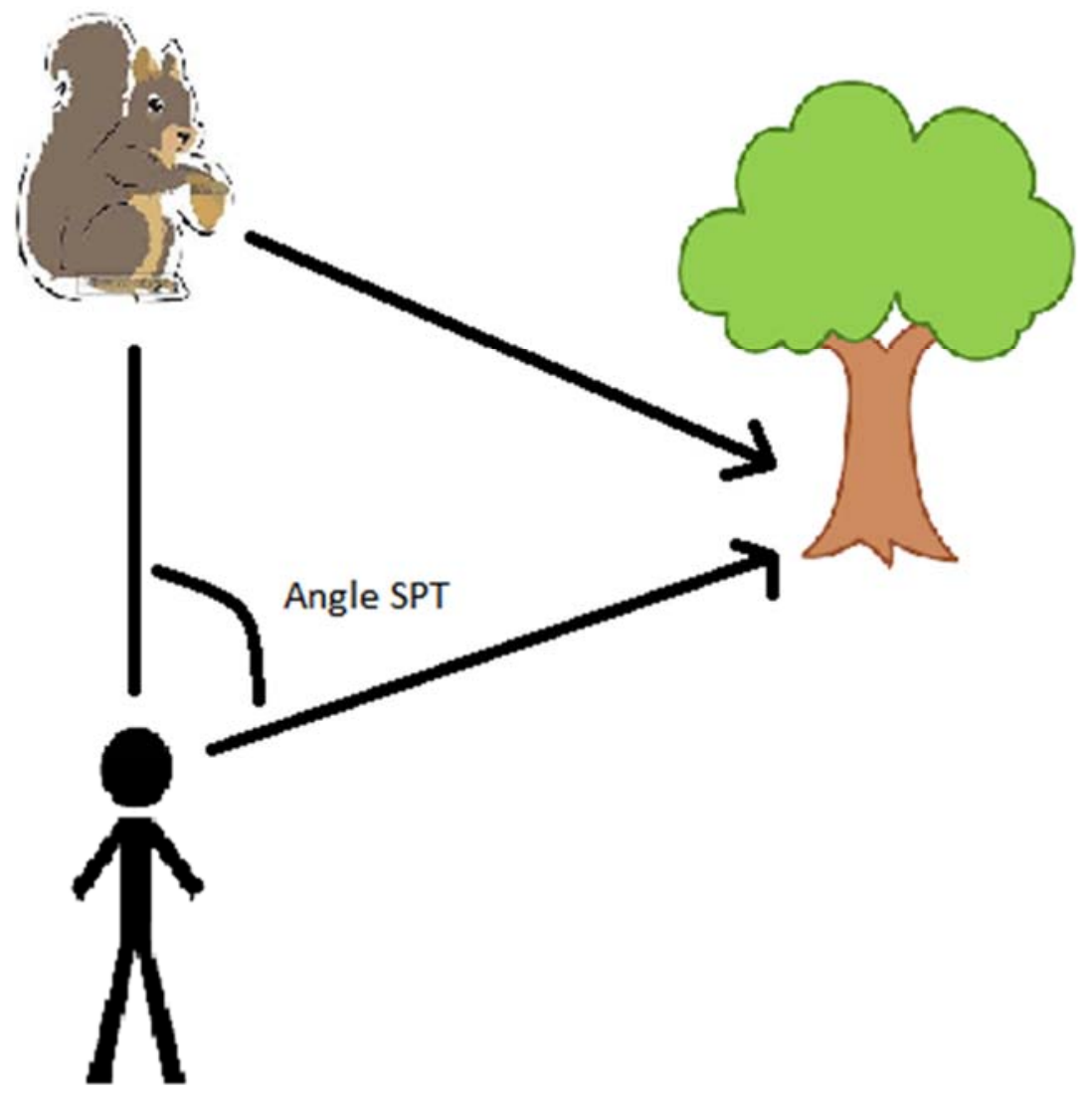

Figure 1. The relationship between the runner, the focal squirrel, and the refuge. Angle SPT is marked with an arc. 


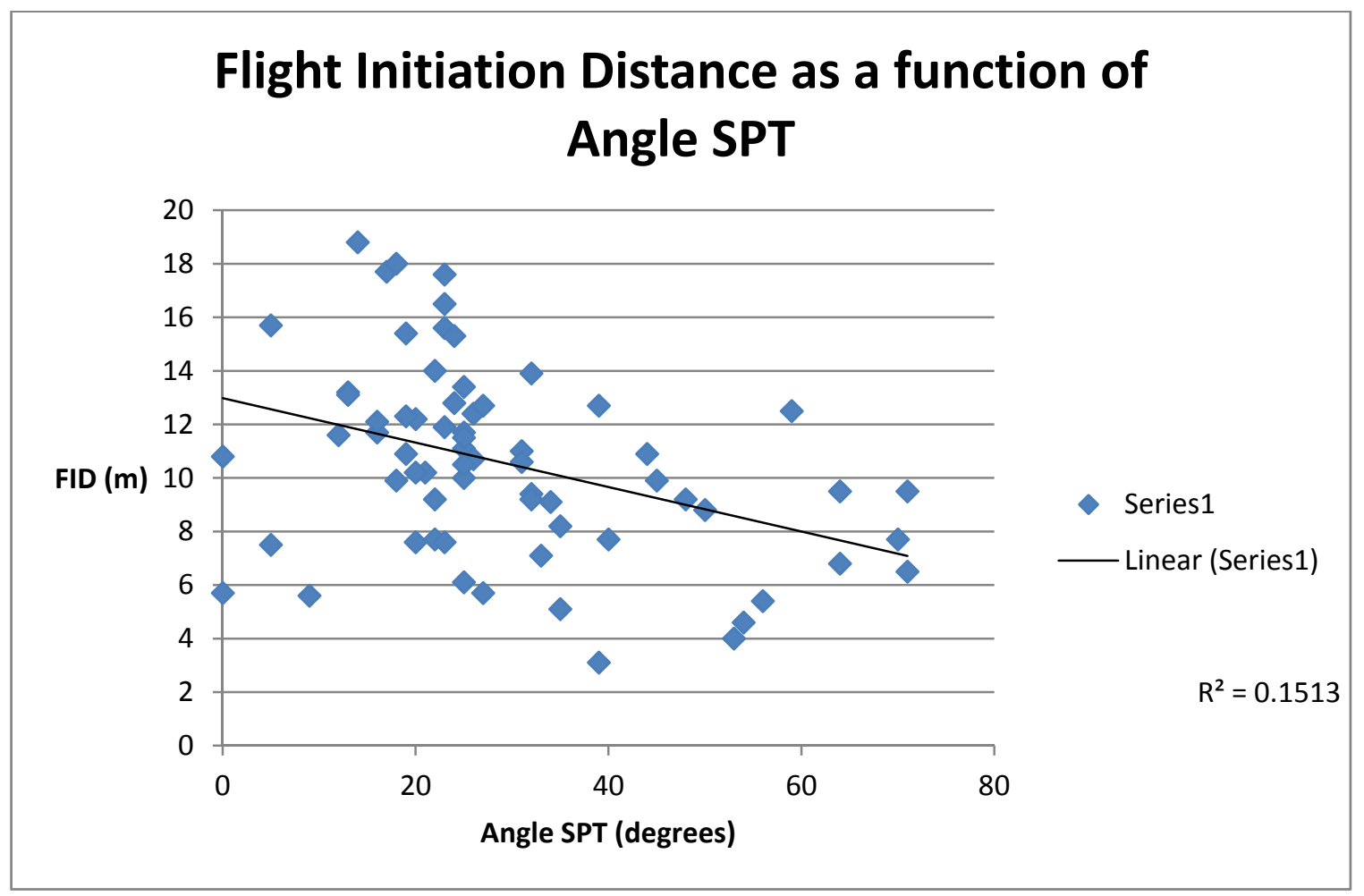

Figure 2. The relationship between angle SPT and flight initiation distance. 


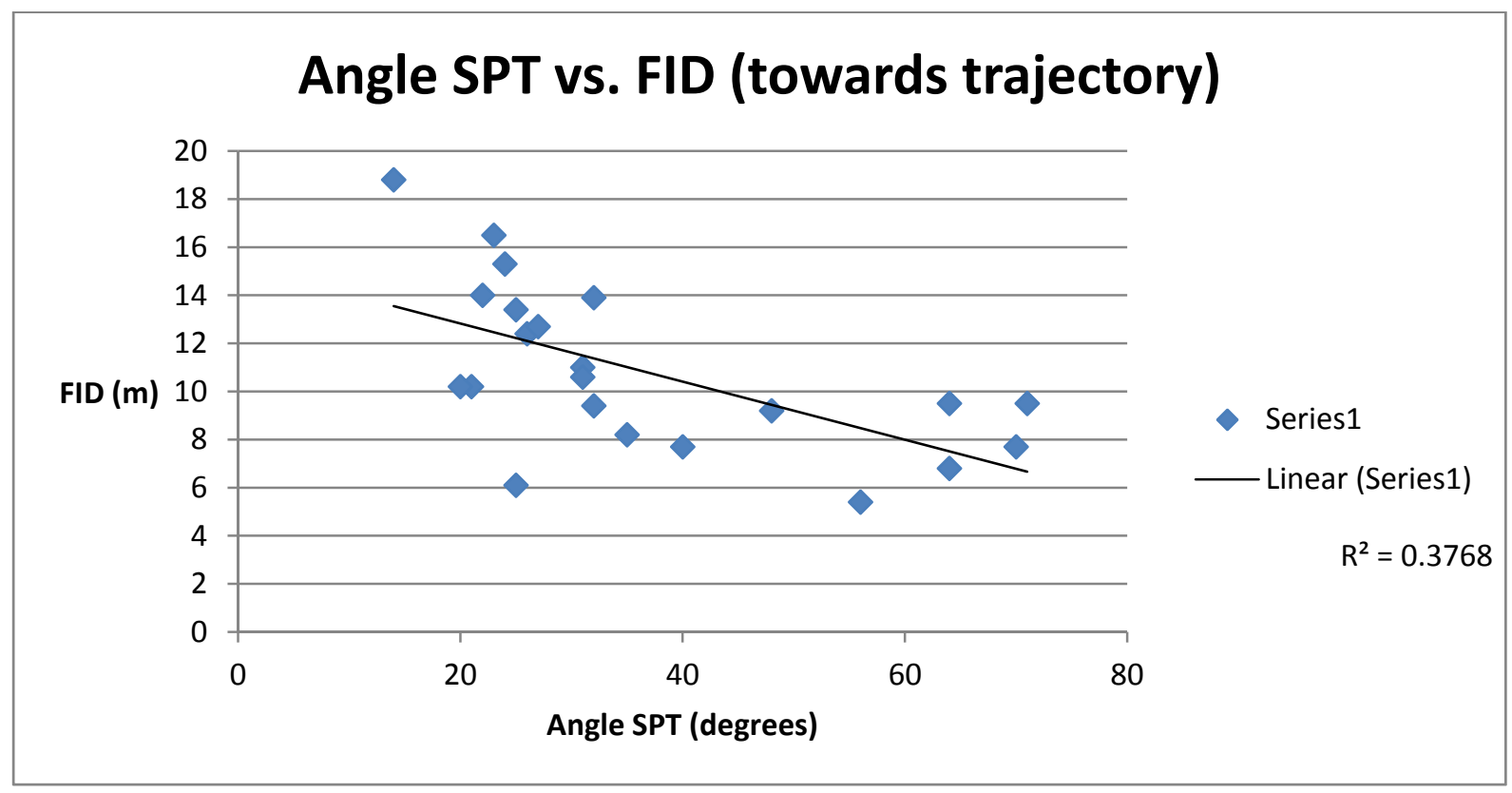

Figure 3. The relationship between angle SPT and flight initiation distance for squirrels that ran towards the approaching threat. 


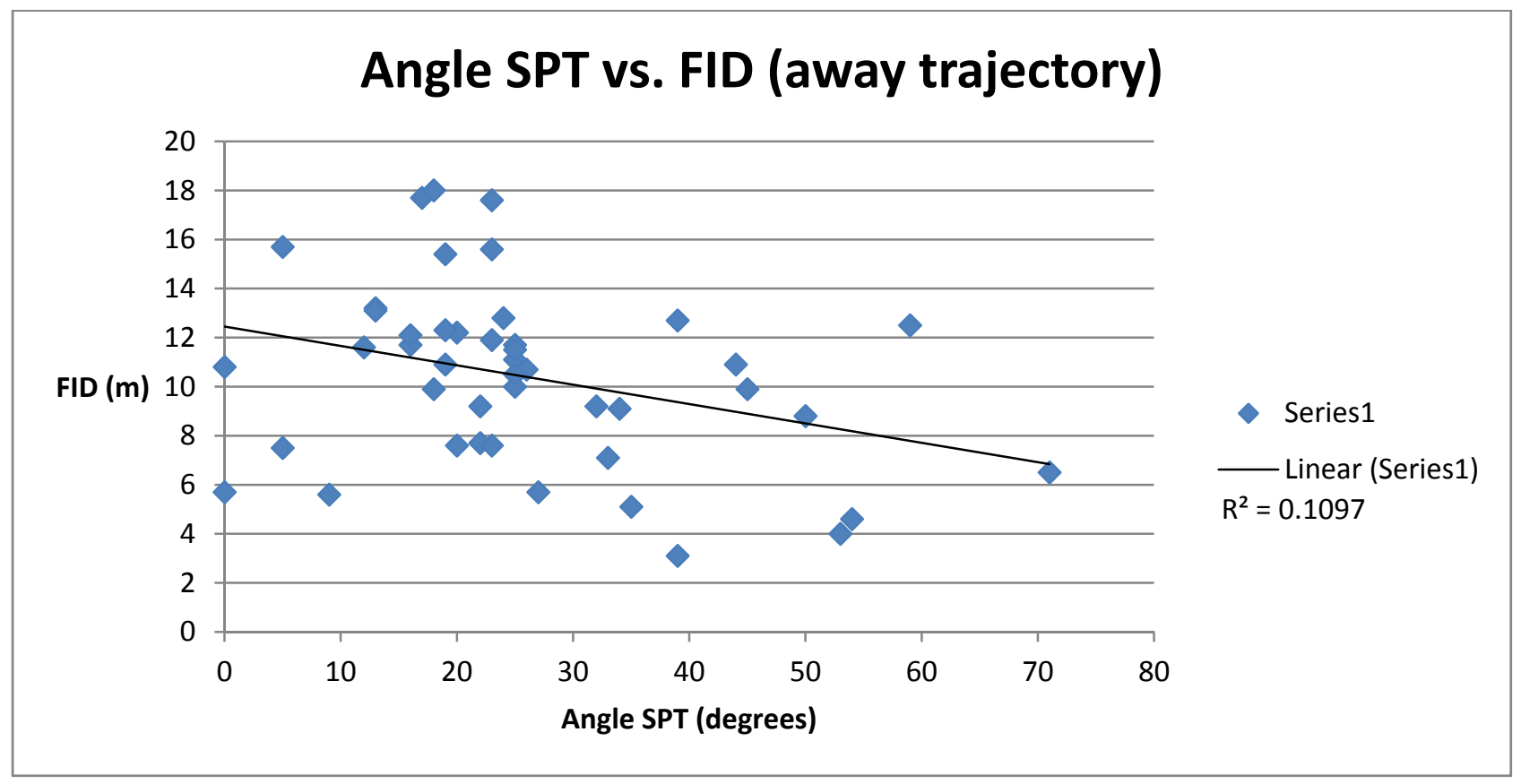

Figure 4. The relationship between angle SPT and flight initiation distance for squirrels that ran away from the approaching threat. 


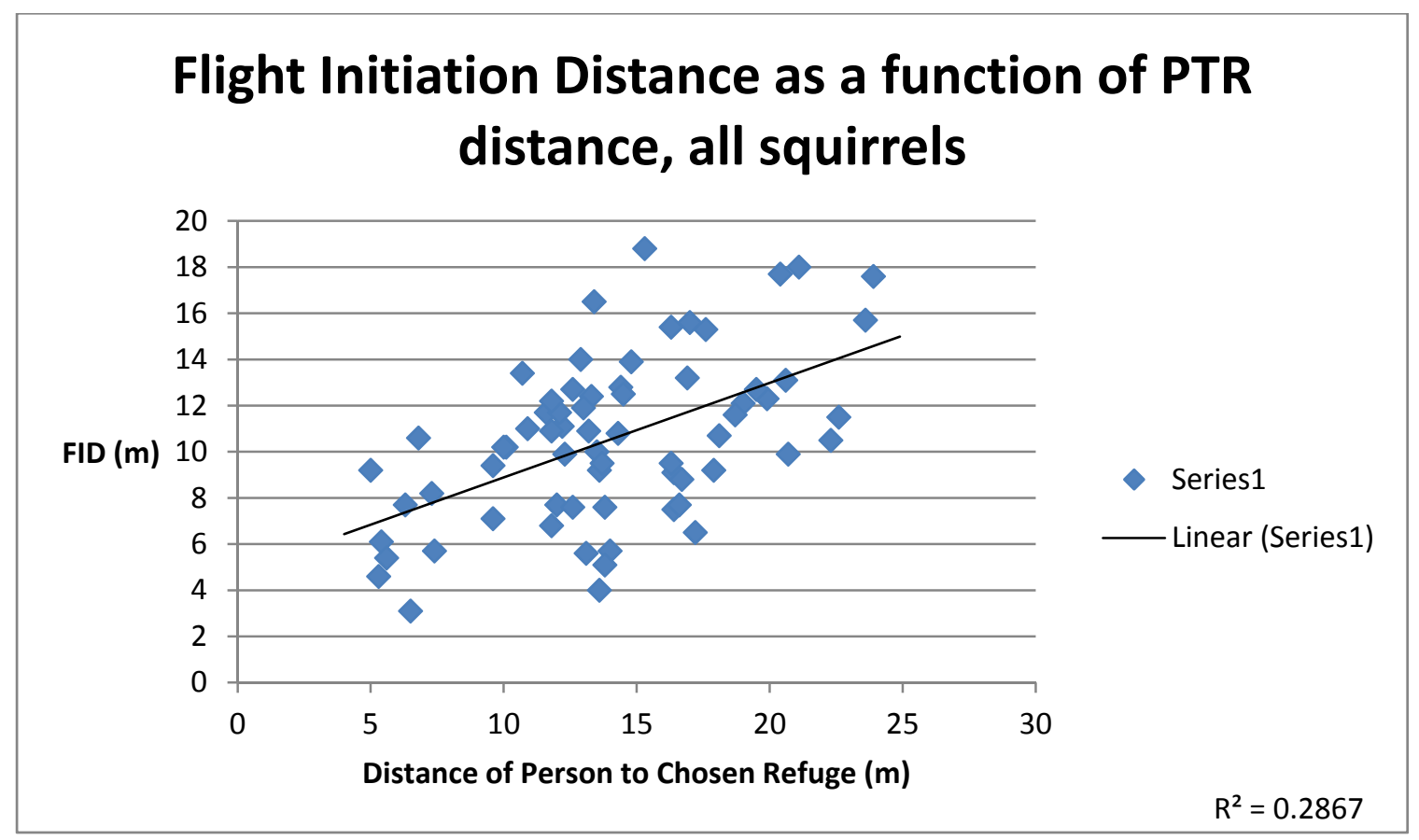

Figure 5. The relationship between the distance of the person (the threat) to the squirrel's chosen refuge and the squirrel's Flight Initiation Distance. 


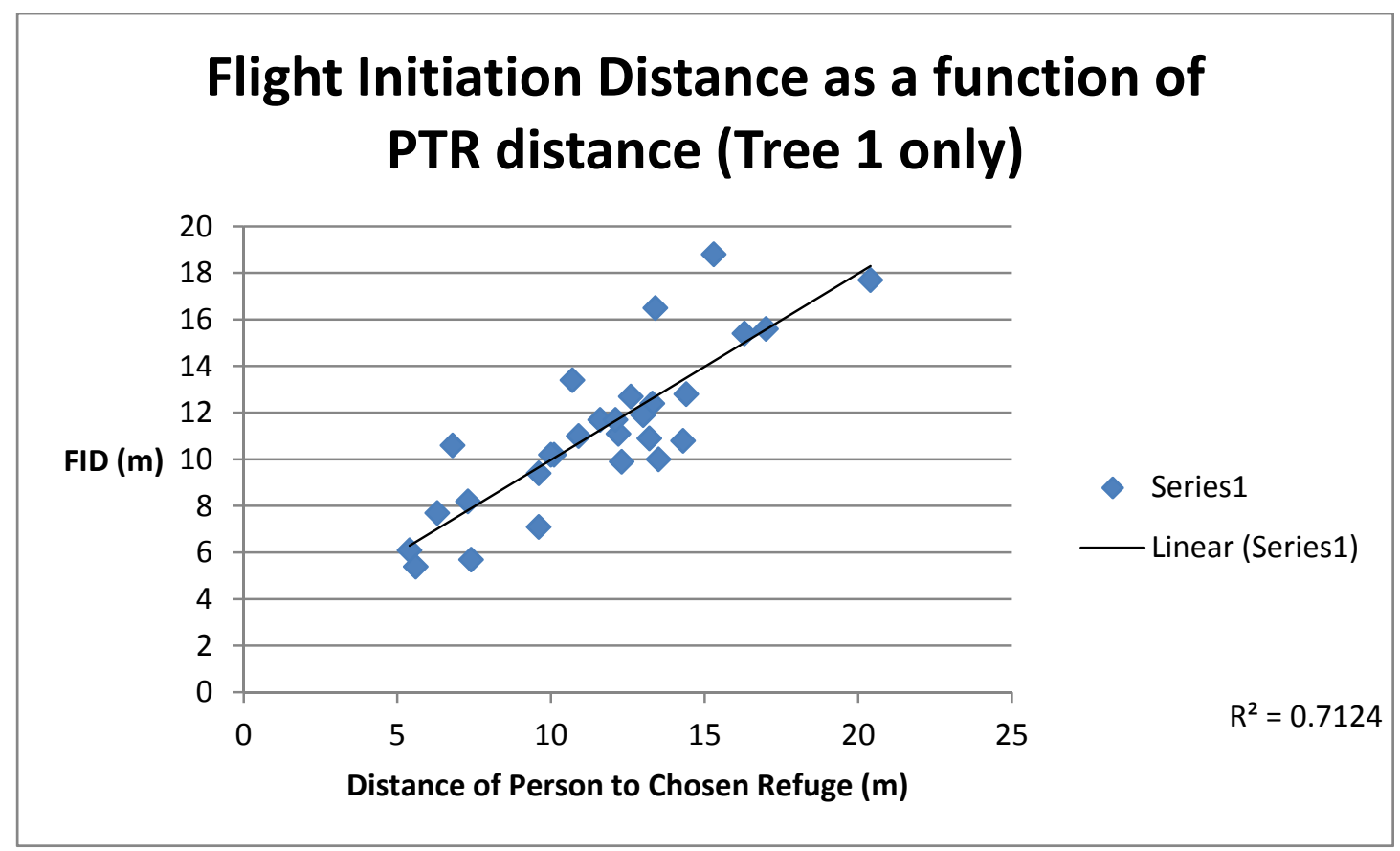

Figure 6. The relationship between PTR distance and FID for squirrels that chose Tree 1. 


\section{Relationship Between PTR and STR, all squirrels}

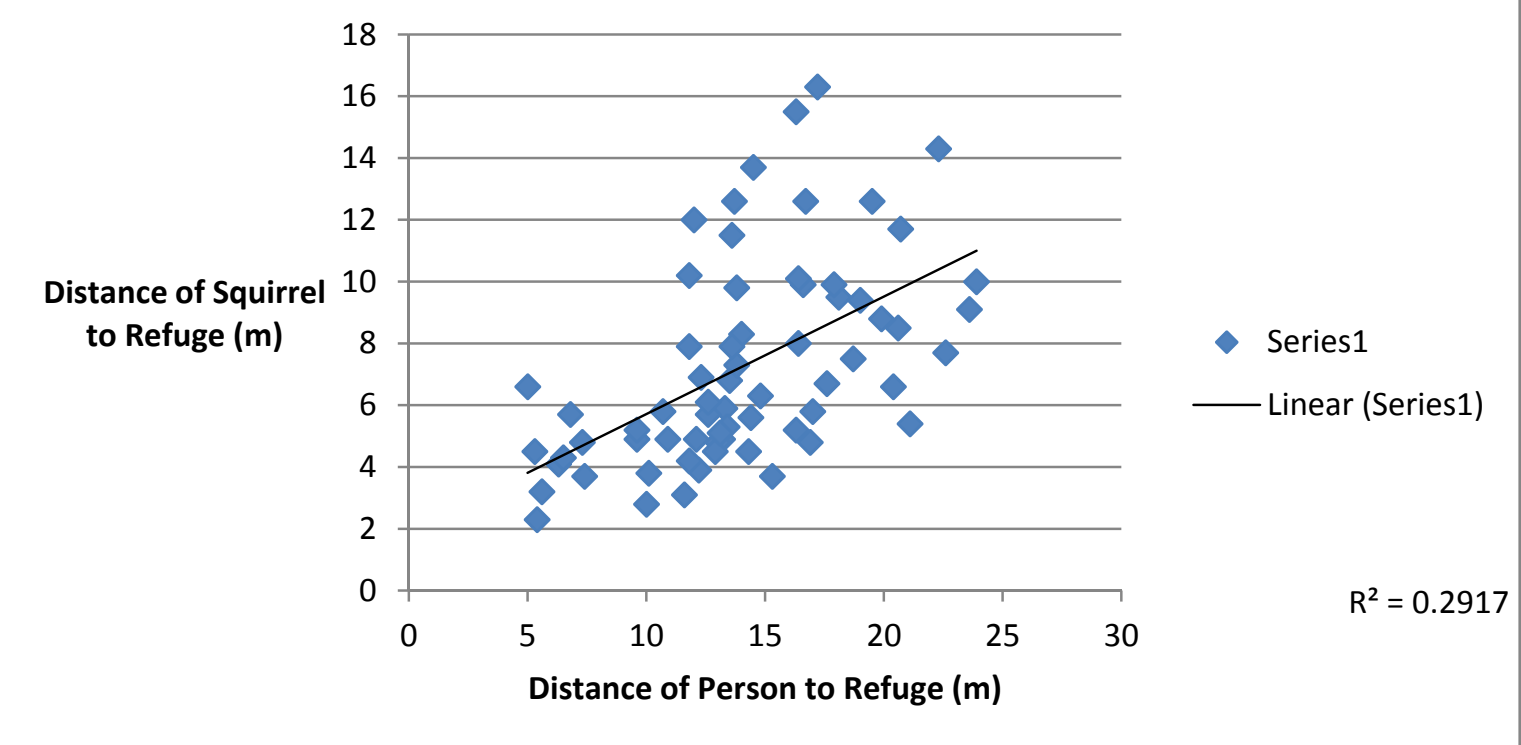

Figure 7. The relationship between the distance of the person to the chosen refuge (PTR) and the distance of the squirrel to the chosen refuge (STR). 


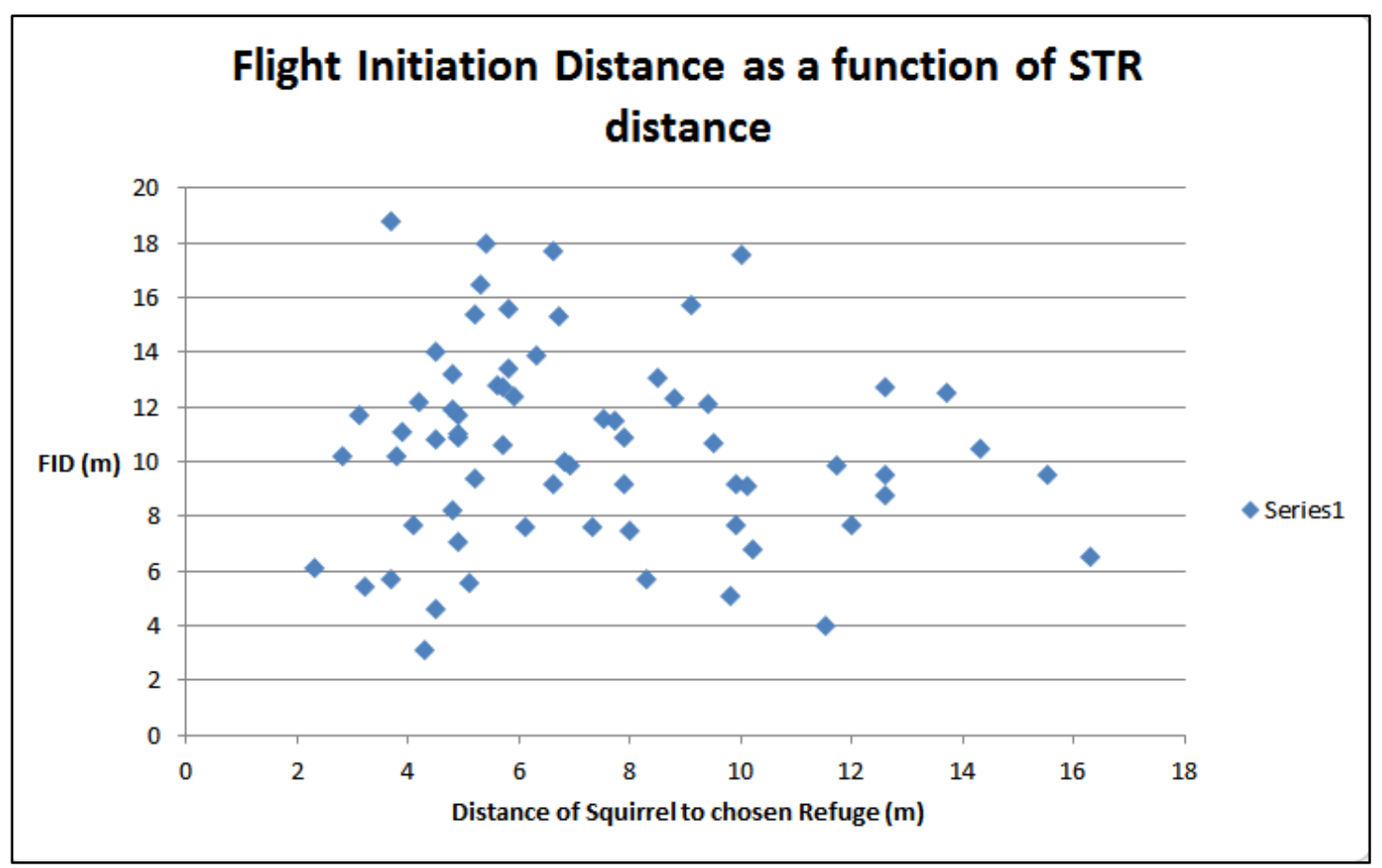

Figure 8. STR distance plotted against flight initiation distance. 


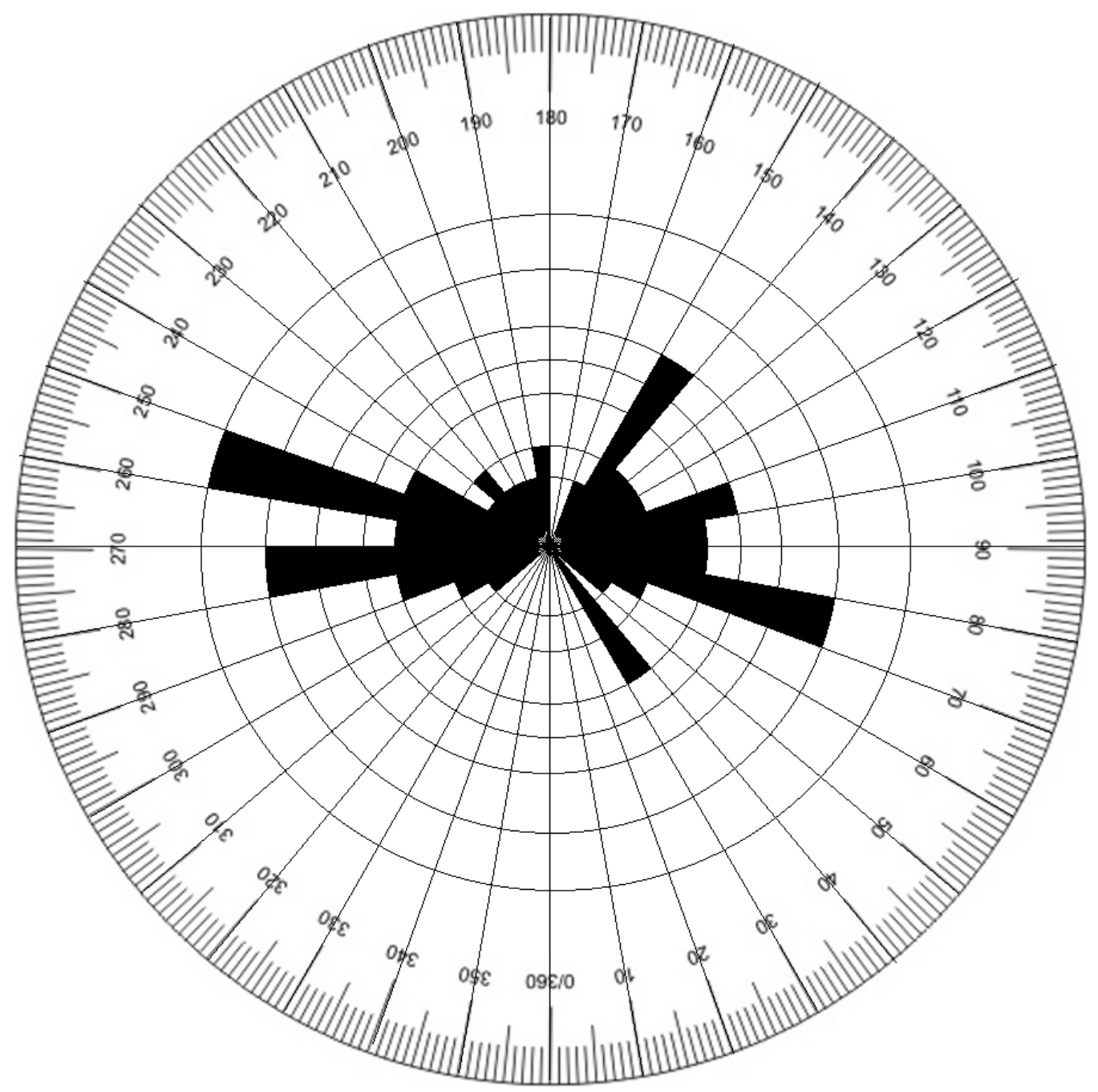

Figure 9. Escape trajectory histogram. The $0^{\circ}$ mark represents the position of the threat, and the center point represents the position of the squirrel. Each ring represents one squirrel, and the histogram displays escape trajectories in 10 degree increments. For example, 7 squirrels ran from $250-259^{\circ} .90^{\circ}-269^{\circ}$ indicates an escape trajectory away from the threat. $270^{\circ}-89^{\circ}$ represents an escape trajectory towards the threat. 


\section{Selection of Tree 1 vs. Trajectory of Tree 1}

\begin{tabular}{|c|c|c|c|}
\hline Chose Tree 1 & (1) Towards & (1) Away & Total \\
\hline Yes & 14 & 14 & 28 \\
\hline No & 30 & 9 & 39 \\
\hline Total & 44 & 23 & 67 \\
\hline
\end{tabular}

Table 1: The relationship between selection (or not) of Tree 1 and the escape trajectory that would have resulted if Tree 1 had been chosen. Note: when a squirrel was forced by scenario constraints to have to run towards the person, the escape path with the shallowest angle was included in the "Away” category. 


\section{Did the chosen escape trajectory lead away} from the approaching threat?

\begin{tabular}{|c|c|c|}
\hline Refuge & Yes & No \\
\hline 1 & 14 & 14 \\
\hline other & 31 & 8 \\
\hline
\end{tabular}

Table 2: The relationship between the chosen refuge and the escape trajectory. "Other" refers to the selection of any tree but the closest (Tree 1). 


\section{Did the chosen refuge maximize the}

\begin{tabular}{|r|lr|l|}
\multicolumn{5}{|c}{ PTR/STR ratio? } \\
\hline Column1 & Yes & No & \\
\hline & & 25 & \\
\hline & & & \\
other & & 18 & \\
\hline
\end{tabular}

Table 3: The relationship between the chosen refuge and maximization of the PTR/STR ratio (distance of the person to the chosen tree/distance of the squirrel to the chosen tree. 


\section{Discussion}

Before the study was conducted, the angle SPT was predicted to vary positively with flight initiation distance, meaning that large SPT measures should correlate with long flight initiation distances. The reasoning behind this was that a large SPT angle would give a predator better ability to cut off the squirrel's path to its refuge. Due to the same effect, the squirrel was predicted to base its refuge choice, at least in part, by minimizing (on a $180^{\circ}$ scale) the SPT angle. In theory, forcing a predator to run in as close to a straight line as possible would reduce that predator's ability to cut the squirrel off, and increase the squirrel's odds of reaching the refuge safely. However, using the SPT angle metric as a predictor of refuge choice was completely unsuccessful. Contingency table analysis showed no significant relationship between minimizing SPT angle and choice of refuge. A relationship was found between the SPT angle and flight initiation distance. Unexpectedly, linear regression showed a statistically significant negative correlation between the size of the angle and the flight initiation distance. This means that the squirrels actually ran away sooner when the runner was (potentially) less able to cut them off. This result may have occurred due to a limitation of the SPT angle measure; refuges with the same SPT angle could be a variety of distances away from both person and squirrel. As shown in Figure 2, very similar SPT angles correlated with a multitude of different flight initiation distances. Because scenarios of different types can share the same SPT angle, making predictions based on the SPT angle by itself is difficult. Multivariate statistical software that can integrate distance and angle measurements will be needed in future research to properly assess the relationship between person, squirrel, and refuge angles and squirrel's decisions about when and where to flee. 
Another unexpected trend was discovered when flight initiation distance was plotted as a function of person-to-refuge distance (PTR) (Figure 5). It was expected that a negative correlation would result, as previous research has shown that an animal will wait longer to flee if the threat is very far away from the refuge. Instead, the data displayed a strong positive correlation, and the squirrels ran away more quickly the farther the person was away from the refuge. It is unlikely that this trend is a statistical anomaly, as the data fit the trendline moderately well (extremely well in the case of the tree 1 squirrels) and the P-value generated by the regression analysis is highly significant. A direct cause-effect relationship makes very little sense in this case; therefore, it is highly probable that the correlation was influenced by at least one other variable.

A good candidate for explanation is the relationship between PTR distance and STR distance. As shown in Figure 7, there is also a strong positive association between these variables. This means that in many cases, when the person was close to the refuge, the squirrel was also close to the refuge, and when the person was far from the refuge, the squirrel was far from the refuge. This helps to explain the PTR-FID relationship, as animals will often flee sooner if they are far from their refuge and will wait longer if they are close to their refuge. (Fong et al. 2009; Cooper and Frederick 2007). However, when STR was plotted directly against FID, the resulting trendline was not statistically significant. (Figure 8). Because direct substitution of STR data for PTR data does not result in the same kind of strong positive correlation with flight initiation distance, other factors must also be in play.

One of these could be escape trajectory. The escape trajectory histogram (Figure 9) shows a high incidence of lateral movement; $52 \%$ of the squirrels took an escape path within $20^{\circ}$ of the $90-270^{\circ}$ plane. Furthermore, $40 \%$ of the squirrels took an escape path that took them 
below the $90-270^{\circ}$ plane, and towards the approaching threat. In at least some cases, the squirrel may have increased its FID if it chose a path that brought it either towards, or very shallowly away from, the approaching threat. Regardless, the high incidence of non-ideal escape trajectories engenders the question "Why did the squirrels choose them?” Part of the answer may come from the constraints of the squirrel's escape scenario; the squirrel always seeks a refuge when fleeing, so in reality only a few points out of the full spectrum of angles presented on the escape trajectory histogram are available to any one squirrel. Differing approach scenarios were used to offset this effect, but due to the small 67 squirrel sample size, some of the histogram segments may be underrepresented not by squirrel choice, but by the lack of trees at those angles. Even so, the strong underrepresentation of escape trajectories that lead sharply away from the threat is greater than can be explained by scenario constraints alone. Only 10 out of 67 squirrels (15\%) took an escape path within $40^{\circ}$ of 180 , or the plane leading directly away from the approaching threat. This reflects the fact that squirrels will choose a closer tree with a less ideal escape trajectory when trees with the best trajectory are located far away from the squirrel.

However, escape trajectory is an important factor in a squirrel's choice of refuge even when not idealized. The data in Tables 2 and 3 show a strong correlation between available escape trajectories and the squirrel's decision to choose or not choose Tree 1 (defined as the closest tree). In the 44 scenarios where Tree 1 was located towards the approaching threat, 30 of the squirrels chose a different refuge. As shown by the data in Table 3, those 30 squirrels (plus 1 whose tree 1 and chosen tree were both located away from the threat) ran to a refuge that was located away from the approaching threat. However, they did not always run to the refuge located the most directly away from the threat. This fact, combined with the 22 squirrels (nearly 
$1 / 3$ of the total) that chose to run towards the threat, indicates that other factors are influencing the squirrel's refuge choice.

One of these factors is the ratio between PTR distance and STR distance. A high PTR/STR ratio maximizes the distance of the person to the refuge and minimizes the distance of the squirrel to the refuge. This measure was a very good predictor of squirrel choice, especially in the group of squirrels that chose Tree 1 . As shown in Table 4, 25 of the 28 squirrels that ran to Tree 1 chose the tree with the highest PTR/STR ratio. When looking at the other group, squirrels that ran to Tree 2 or farther, the PTR/STR ratio does not appear to be a good predictor of refuge choice. This is true when only the highest ratio is given consideration; when the second-highest ratio is included, the result is dramatic. 35 out of the 39 squirrels (90\%) that chose Tree 2 or farther selected a refuge with either the highest or second-highest PTR/STR ratio. These results are partially confounded by the fact that Tree 1 was overrepresented across the data set as the tree with the best PTR/STR ratio and Tree 3 was underrepresented. Due to the high incidence of Tree 1 as the tree with the best PTR/STR ratio, it is possible that some of the Tree 1 squirrels that chose the best ratio were in actuality just choosing the closest tree, and the fact that it was also the tree with the best ratio was coincidental. In further research, a larger data set and careful scenario selection will allow better differentiation between the influence of STR distance and the influence of the PTR/STR ratio.

\section{Conclusions}

Counter to the prediction of this study, the SPT angle measured by itself was not a predictor of a squirrel's refuge choice, and it had only a marginally significant relationship with flight initiation distance. Perhaps it is relevant to an aspect of the research scenario not analyzed here, or would show more significant results with a bigger sample size. It is more likely, 
however, that it needs to be integrated with the distance variables and the other angles, and that the combination of some or all of these factors is the best way to make predictions about flight initiation distance and refuge choice. A larger sample size and multivariate statistics will be needed to properly integrate and examine these variables.

The effect of the relative positions of squirrel, person, and refuges on flight initiation distance provided some intriguing and unexpected results. More research is needed to determine whether or not PTR distance shares a direct, positive relationship with flight initiation distance or whether the relationship discovered in this study is an artifact of other variables. The STR distances likely had some effect but are not able to fully explain the PTR-FID relationship. Determining whether or not this relationship is actually representative of a squirrel's FID decision making is certainly worth some further pursuit, because it is completely counteractive to the results of pretty much all of the previous research that has been done on flight initiation distance and the relative distances of predator and refuge.

The other main prediction of this study, that the relative positioning of squirrel, person, and potential refuges could be used to determine the squirrel's refuge choice, was better supported by the data. The data collected in this study upheld the prediction that both escape trajectory and the PTR/STR ratio have a strong influence on a squirrel's choice of refuge. (Though the significance of the ratio data is partially confounded by the fact that Tree 1 was overrepresented as the tree with the best ratio). This result is very exciting, because it means that squirrels are capable of assessing multiple factors in the few moments they have before they must flee the oncoming threat. Instead of simply running to the closest tree or the tree most directly away from the approaching threat, the squirrel makes its choice of refuge by judging the relative positions of itself to each tree, the person to each tree, and the escape trajectory to each 
tree. For this study, it was not possible to determine the "best tree" in each individual scenario

because many of them contained two trees that had very good combinations of escape trajectory

and PTR/STR ratio. However, with a larger data set and multivariate data analysis software, it

should be possible to create a much better predictive model for squirrel refuge choice.

\section{References}

Camp, M.J., Rachlow, J.L., Woods, B.A., Johnson, T.R., Shipley, L.A., Zeh, D., 2012. When to Run and When to Hide: The Influence of Concealment, Visibility, and Proximity to Refugia on Perceptions of Risk. Ethology 118, 1010-1017.

Cardenas, Y.L., Shen, B., Zung, L., Blumstein, D.T., 2005. Evaluating temporal and spatial margins of safety in galahs. Anim. Behav. 70, 1395-1399.

Cloyed, C.S., Eason, P.K., 2015. Night and day: comparing flight initiation dynamics in two closely related species of true frogs. Journal of Zoology 295, 206-213.

Cooper, W.E., 2011. Influence of Some Potential Predation Risk Factors and Interaction between Predation Risk and Cost of Fleeing on Escape by the Lizard Sceloporus virgatus. Ethology 117, 620-629.

Cooper, W.E., Frederick, W.G., 2007. Optimal flight initiation distance. J. Theor. Biol. 244, 59-67.

Cooper, W.E., Wilson, D.S., 2007. Beyond optimal escape theory: microhabitats as well as predation risk affect escape and refuge use by the phrynosomatid lizard Sceloporus virgatus. Behaviour 144, 1235-1254.

Domenici, P., Blagburn, J.M., Bacon, J.P., 2011. Animal escapology II: escape trajectory case studies. J. Exp. Biol. 214, 2474-2494.

Eason, P.K., Sherman, P.T., Rankin, O., Coleman, B., 2006. Factors affecting flight initiation distance in American robins. J. Wildl. Manage. 70, 1796-1800.

Engelhardt, S.C., Weladji, R.B., 2011. Effects of levels of human exposure on flight initiation distance and distance to refuge in foraging eastern gray squirrels (Sciurus carolinensis). Can. J. Zool.-Rev. Can. Zool. 89, 823-830.

Fernandez-Juricic, E., Venier, M.P., Renison, D., Blumstein, D.T., 2005. Sensitivity of wildlife to spatial patterns of recreationist behavior: A critical assessment of minimum approaching distances and buffer areas for grassland birds. Biol. Conserv. 125, 225-235.

Fong, T.E., DeLong, T.W., Hogan, S.B., Blumstein, D.T., 2009. The importance of indirect cues for white-browed sparrow-weaver (Plocepasser mahali) risk assessment. Acta Ethol. 12, 79-85.

Guay, P.-J., Lorenz, R.D.A., Robinson, R.W., Symonds, M.R.E., Weston, M.A., Wright, J., 2013. Distance from Water, Sex and Approach Direction Influence Flight Distances Among Habituated Black Swans. Ethology 119, 552-558.

Kramer, D.L., Bonenfant, M., 1997. Direction of predator approach and the decision to flee to a refuge. Anim. Behav. 54, 289-295.

Rodriguez-Prieto, I., Fernandez-Juricic, E., Martin, J., Regis, Y., 2009. Antipredator behavior in blackbirds: habituation complements risk allocation. Behav. Ecol. 20, 371-377.

Stankowich, T., Blumstein, D.T., 2005. Fear in animals: a meta-analysis and review of risk assessment. Proc. R. Soc. Lond. Ser. B-Biol. Sci. 272, 2627-2634. 


\section{Acknowledgements}

Researchers:

- Dr. James Alexander, Biology Dept., University of Louisville

- Dr. Perri Eason, Biology Dept., University of Louisville

- Dr. Peter Sherman, research assistant 